\title{
Single case research method to understand user experience in online stock broking
}

\begin{abstract}
A single-case research method was chosen to explore further the user experience in online stock trading. This research focuses on part-time online stockbrokers. The study discusses the experiences of traders when conducting online stock trading and links it with the attributes of the user experience. The results of the study highlight that a significantly positive experience when executing online stock trading will influence users to use online stock trading in the future. It is envisaged that the discussion of the results and user experience attributes will enrich the knowledge of the online stock trading system, as well as the design of large-scale websites where effective and efficient system usage in relation to locating information is key to user success.
\end{abstract}

Keyword: Online stock broking; User experience; Part-time traders 